\title{
Analysis of Mobile Business Processes for the Design of Mobile Information Systems
}

\author{
André Köhler, Volker Gruhn \\ University of Leipzig \\ Chair of Applied Telematics / e-Business \\ Klostergasse 3 \\ 04109 Leipzig, Germany \\ \{koehler, gruhn\}@ebus.informatik.uni-leipzig.de
}

\begin{abstract}
The adoption of mobile technologies into companies frequently follows a technology -driven approach without precise knowledge about the potential benefits that may be realised. Especially in larger organisations with complex business processes, a systematic procedure is required if a verifiable economic benefit is to be created by the use of mobile technologies. Therefore, the term "mobile business process", as well as requirements for information systems applied in such processes, are defined in this paper. Subsequently, we introduce a procedure for the systematical analysis of the distributed structure of a business process model in order to identify mobile sub-processes. For that purpose, the method Mobile Process Landscaping is used to decompose a process model into different levels of detail. The method aims to manage the complexity and limit the process analysis to the potentially mobile subprocesses from the beginning. The result of the analysis can be used on the one hand as a foundation for the redesign of the business processes and on the other hand for the requirements engineering of mobile information systems. An application of this method is shown by the example of business processes in the insurance industry.
\end{abstract}

\section{Motivation and Related Work}

\subsection{Motivation}

The orientation towards business processes and their optimisation has been an important issue for some years [1]. The identification of opportunities for cost reduction, as well as integrated IT-support for processes are increasingly coming to the fore, with technologies supporting mobility making an important contribution. Particular potential benefits lie in the seamless, company-comprehensive integration of all partners participating in the business process, especially when this process is distributed [2]. Thus, each process-step on the value chain can be connected directly to the operational information processing, so the goal-oriented control of the whole business process becomes feasible [3]. 
To exploit these advantages effectively, specialized information systems, supporting not only the business process but handling the mobility of the process-executing person if necessary, are required. In order to develop such systems we propose the method Mobile Process Landscaping. This method allows the goal-oriented analysis of a process model and its distribution structure to explore mobilisation opportunities.

\subsection{Related Work}

A number of recent publications showed that certain activities can be improved regarding efficiency and effectiveness through the use of mobile technologies (see e.g. [4], [5]). The mentioned examples are case studies describing successfully released solutions in certain companies, however, how these companies choose the described business processes and activities for the use of mobile technologies remains open questions.

Frequently, a technology-driven approach can be observed for realising potential benefits, which adjusts processes corresponding to the available features of certain mobile devices. But often, a large number of complex processes with many involved people prevails, e.g. in large companies and corporate groups. Such an approach may then lead to wrong decisions, especially in the long term. In our opinion, the process of decision-making about the use and the design of a mobile information system needs to be systematic and comprehensible.

For this purpose, section 2 deals with basic characteristics of mobility in connection with business processes and information systems. Section 2.1 defines the term "mobile business process" and illustrates our understanding of mobility from an application-oriented point of view. Hence, requirements for the development of mobile information systems can be deduced, as illustrated in section 2.2. Subsequently, the Mobile Process Landscaping method is explained by an example from the insurance industry (section 3 ). The need for further research is pointed out in section 4 .

\section{Mobility within Business Processes and Information Systems}

\subsection{Mobility in Business Processes}

The term "business process" was defined by numerous authors (i.e. [6], [7], [1]). Below, we follow the commonly used definition of Davenport [7] according to which a business process can be understood as "a specific ordering of work activities across time and place, with a beginning, an end, and clearly identified inputs and outputs: a structure for action." A business process can be decomposed in different levels into process partitions. Thus, a business process can be understood as an abstract description of workflows in a company. The actual occurrence of such a business process in reality is called a business process instance.

In the following, only business processes with a specific distribution structure and thus a certain mobility of the process-executing persons are considered. We propose that mobility is given when for at least one process partition: 
a) there is an "uncertainty of location",

b) this "uncertainty of location" is externally determined, and

c) a cooperation with external resources (from the process-point of view) is needed in the execution of the process .

The assumption a) is based on the concept of "location uncertainty" by Valiente and van der Heijden [8], according to which the place of the execution of an activity can be different in different instances of the business process or the places can change during the execution of an activity. Thus, we deal with a mobile process partition within a business process. Because multiple mobile process partitions are conceivable, and a mobile process partition often affects the whole business process, the complete business process is called "mobile business process".

Further on, assumption b) presumes that the location uncertainty is caused by external fictors and that the process-executing person has therefore no freedom of choice regarding the place of the process execution. Assumption c) restricts the term "mobile business process" to the necessity of cooperation with external resources within the considered process partition, for instance caused by the need for communication or coordination with other persons or interaction with other objects.

For example, at the moment of the customer inquiry the place where the field staff will meet a customer for sales conversation is unknown (location uncertainty). During the sales conversation, the field staff interacts with the customer and possibly simu ltaneously with the information system of the company (cooperation with external resources). Thus, the business process is a mobile one. In contrast, an employee working on office duty, moving his wireless LAN-connected notebook to the conference room for a short time, does not conduct a mobile business process because there is no compuls ory location uncertainty, i.e. his movement is not externally triggered.

The above definition of mobility is deduced from the characteristics of the task the process-executing persons need to perform in the mobile process partition. The defin ition of mobile business processes does not imply the existence of any automatic information processing in any way. In fact, the following section will show, how the need for an information system to support mobile business processes can be identified.

\subsection{Mobile Information Systems in Mobile Business Processes}

An information system can be defined as "a set of interrelated components that collect (or retrieve), process, store, and distribute information to support decision making, coordination, and control in an organisation", as proposed in [9]. Because of the mentioned specifics of mobile business processes the information system must be adapted to deal with the location uncertainty within activities. An information system that is adapted to location uncertainty will be called "mobile information system" in the following. Its outstanding characteristic is the ability to provide coordination, control and decision support within the business process under the restriction of spatial limitations [8].

Thus, a mobile information system can on the one hand support mobile business processes by the improvement of efficiency during their execution and on the other 
hand create premises for turning so far not mobile business processes into mobile ones. In the following, we assume that an information system can be transformed into a mobile information system by adding a mobile element to it. To enable this transformation, the mobile element of an information system needs to allow its use for a mobile activity just as well as if the activity was not mobile.

A number of recent publications showed in case studies how mobile technologies can be used to improve workflows and single activities in terms of efficiency and duration. Unfortunately, it often remains unexplained how the concerned companies chose the corresponding business processes and activities for bringing mobile technologies into operation. If there are manageable processes with just a few people involved, the impacts caused by the use of mobile technologies, as well as the effects of the process changes can probably be estimated roughly.

In [5], the mobile equipment of taxi drivers in Stockholm is described, that was introduced with the aim to improve the dispatching process. "Based on a number of requirements the company identified an opportunity to ameliorate the dispatching process by the use of improved mobile technology based on GPS, radio communication, and information system technology." The exciting question how these requirements and opportunities were acquired, rema ins open, unfortunately.

In the shown example, business processes are adjusted to the possibilities offered of mobile technology, starting from available mobile devices and mobile networks. In doing so, they follow a technology-driven approach to realise potential benefits. As soon as we are dealing with a large amount of complex processes, in which numerous persons are involved (as it is typical for large companies and corporate groups), such a procedure could lead to wrong decisions, especially in the long term. The decision about the use and the design of a mobile element for existing information systems has to be made systematically and traceably in our opinion.

Thus, we see the necessity of representing the workflow in a company by a specialised process model in order to identify potential process improvements on the basis of the definition of mobile business processes. Subsequently, the requirements for the creation of the mobile element of the existing information system need to be defined in order to be able to examine whether the mobile technology and devices meet the demands. For this procedure, we propose the following steps [10]:

(1) Analysis of the process model and identification of mobile business processes.

(2) Redesign of the identified process partitions (under the assumption of the producibility of a mobile element for the information system).

(3) Specification of the mobile element as required by the new business processes.

(4) Validation of the profitability of the change (valuation of the relationship between estimated costs and forecast benefit).

(5) Implementation of the change (actual redesign of the processes and development of the mobile element).

In the following, we will describe how the analysis of existing processes and the identification of mobile potentials in step (1) can be conducted by the use of the Mo- 
bile Process Landscaping method. Steps (2) to (4) are beyond the scope of this paper, and (5) is rather a point for further research, as outlined in the conclusion.

\section{Identification of Mobile Business Processes through Mobile Process Landscaping}

\subsection{Specialisation of Process Landscaping}

With Mobile Process Landscaping, we propose a systematical approach for identifying and analysing mobile business processes. It is a specialisation of the "Process Landscaping" method [11]. The idea of the method is to split the modelling of processes into different tiers, starting with a coarse and simplified form of the process description and then increasing the level of detail with each tier. Other approaches for the modelling of (mobile) processes (see e.g. [12], [8], [13]) neglect the question of the level of detail. We believe that in practice, this will lead to difficulties in the description and analysis caused by different understandings of processes [11].

The aim of the proposed procedure is twofold: on one hand, it should help to handle the complexity of processes. On the other hand, it should help to recognise the distribution structure very early. Thus, the method can only be applied to distributed process structures. At an early stage, process partitions with mobile potentials can be located. The process analysis should just at these points be continued in order to minimise the analysis effort. For the presentation of the different levels of detail, we propose four different tiers, that are determined by the global company structure.

The first level of detail represents the coarse company structure, i.e. the main elements of the value chain. The processes identified on this level are called "core processes" in the process model. A result of this description could be "There is a sales process. "On the second level, the processes are described on the basis of the tasks and functions within the core processes on the first level. These processes are called "sub-processes" in the process model. A core process can be composed of multiple sub-processes. On this level, we could answer the question "What is the field staff doing in the sales process?" The third level describes the activities in the processes identified on the second level. In the process model, those processes are called "activities." A sub-process can consist of multiple activities. On this level, it should be possible to answer the question "How is the field staff doing it?" On the fourth level, workflows for the above defined activities are described. If an information system is used, this level could describe dialog structures and data flows. These objects are called "information objects" in the model. At this point one could ask: "How is the workflow organized?"

Figure 1 shows the correlation between the levels of detail in the process model and the real world according to [14]. Applying this procedure in a top-down-approach to process modelling, we identify the process partitions which need to be redesigned in order to be supported by a mobile information system. Our aim is the identification of mobile potentials on each level of detail. A refinement of the process model on the next level of detail is just needed for identified partitions. This way, the complexity can be reduced and the effort for the analysis can be minimised. 


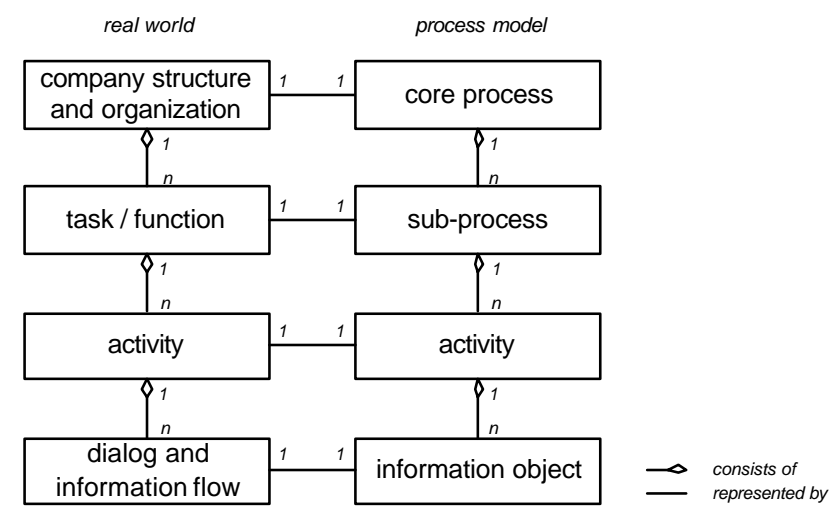

Fig. 1. Correlation between the levels of detail in the process model and the real world

\subsection{Notation of the Process Model}

Process models can be described by different notations. Established approaches are e.g. (high-level) petri-nets [15], UML Activity Diagrams [16], Event-Driven Process Chain Markup Language [17], Business Process Modeling Notation [18] and the Business Process Modeling Language [19], of which [20] provides an apt overview. These approaches are widely spread and tested by practical experience, so we do not want to add a new one. In order to identify mobile process partitions, for the creation of a process landscape it is necessary to describe both the spatial distribution and the cooperation with external resources, as demanded by the definition in section 2.2. In the approaches given above, this is not the case or realised very differently. In the following we abstract from these approaches and choose a simplified notation fulfilling the given aspects of process modelling completely.

Organisational units whose subjects (single persons or groups of persons) are not spatially separated from each other are symbolized by a grey rectangle with rounded corners. Processes inside organisational units are represented by a white rectangle. Relations between processes inside an organisational unit are symbolized by a solid line (internal interaction). A dashed line indicates a relation between processes in different organisational units (external interactions).

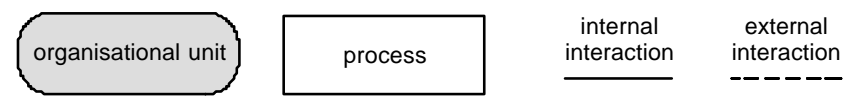

Fig. 2. Symbols for the process model

On the first level of detail, the relations between the processes are undefined in terms of their order (unsigned edges). Only the existence of a relationship is shown. Starting from the second level of detail, signed edges are used to show the logical and temporal order of the processes. The aim of this kind of description is to identify mobile potentials within the considered processes which, according to our definition, is 
induced by an externally determined location uncertainty as well as a cooperation with external resources.

An externally determined location uncertainty is present in processes that cannot be allocated clearly to a single organisational unit. This means, multiple, spatially separated persons or groups of persons are involved in their execution. This is a necessary, but not sufficient condition for a mobile business process. If such a partition is identified in the process model, we assume a potential mobility that can be approved or disproved by a stepwise refinement of the process partition. The potential mobile process partition is indicated in the graphical representation by different processes lying on top of each other. The cooperation with external resources is shown by a dashed line, indicating an exchange of information between different process partitions across organisational units. This is also a necessary, but not sufficient condition for a mobile business process. Again, the potential mobility can be approved or disproved by a stepwise refinement of the process partition.

\subsection{Mobile Process Landscaping Exemplified in the Insurance Industry}

In the following, the application of Mobile Process Landscaping, is shown using examples from the insurance industry. We assume that during the preparation of the process analysis four spatially separated organisational units could be identified: the company itself, the fie ld staff, customers and partners (Figure 3).

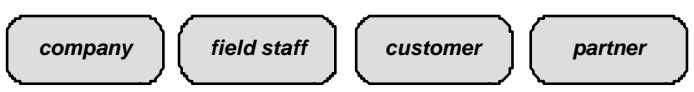

Fig. 3. Spatially separated organisational units

In the first step of the analysis the core processes of the company are identified on the basis of the company structure and assigned to the organisational units. Figure 4 shows the results of this step, completing the analysis on the first level of detail.

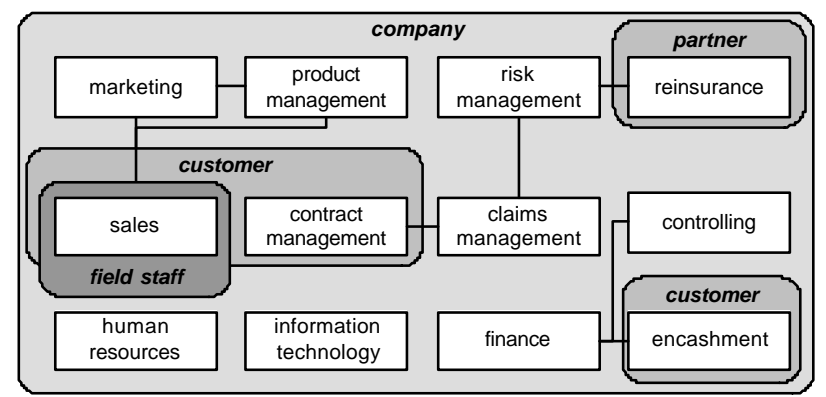

Fig. 4. Core processes in an insurance company

It is noticeable that there re relationships between some core processes of the company. Furthermore, it is obvious that in some processes (sales, contract management, reinsurance, encashment) different, spatially separated organisational units (company, field staff, customer, partner) are involved. By definition, those core proc- 
esses are potential mobile processes. A refinement of the process model should therefore only be conducted at these specific core processes. For the further process analysis, we limit the examination to the core process "sales" here. Within this process, tasks, functions and their relationships need to be defined, as shown in Figure 5.

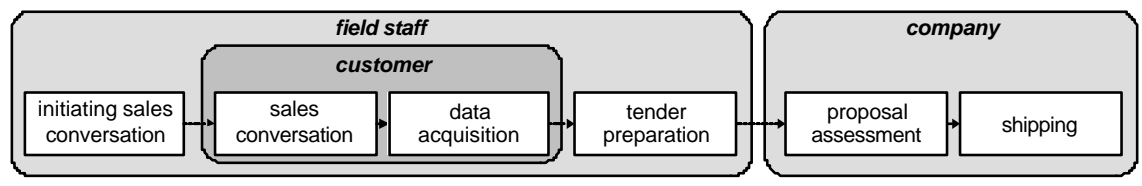

Fig. 5. Sub-processes for the core process "sales"

The field staff initiates a sales conversation and calls the customer. Both participate in the sales conversation as well as in the ensuing data acquisition, so the corresponding sub-processes are potentially mobile. In the following, the field staff returns to the agency for preparing the tender and sends it via mail to the company (cooperation with external resources). This is a potentially mobile business process as well. The company examines the tender before it is shipped to the customer. Within the process "tender preparation", classified as potentially mobile, the third level of detail is now refined (Figure 6). The field staff submits the customer data to the company. There, the valuation of risk is performed in order to calculate the rate and generate the tender. During the submission of the customer data, the boundary between the organis ational units "field staff" and "company" is crossed. Thus, this activity is potentially mobile.

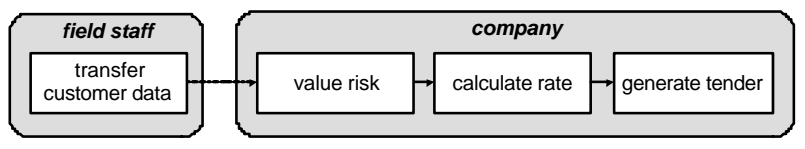

Fig. 6. Activities for sub-process "tender preparation"

Finally, we consider the fourth and last level of detail (Figure 7). The field staff prints a data sheet for submitting the customer data and sends it to the company via mail. There, the data is again acquired and saved. Among the information objects "send mail" and "acquire data", an information exchange across the boundaries of spatially separated organisational units takes place, so both information objects are potentially mobile.

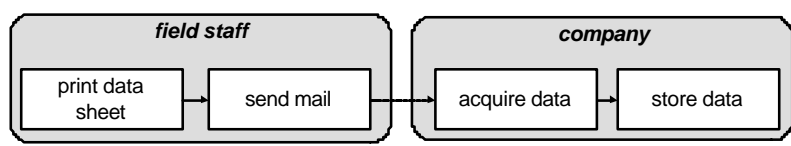

Fig. 7. Information objects for activity "transfer customer data"

Furthermore it is noticeable, that the organisational boundary between "transfer customer data" and "value risk" (Figure 6) has moved more into the activity "transfer customer data". This is a result of the task decomposition. This way, the last level of detail of the analysis is reached. The information objects "send mail" and "acquire 
data" highlight a process partition which renders the activity "transfer customer data", the sub process "tender preparation" and the core process "sales" potentially mobile.

At this point, a redesign of the process can be applied in order to develop a mobile information system, as proposed in step (2) of our procedure in section 2.2. All processes identified as potentially mobile as well as their preliminary and subsequent elements, come into question for a redesign. In our example, displayed in figure 7, those processes are "send mail" and "acquire data", as well as the preliminary process "print data sheet" and the subsequent process "store data". In this case, the whole process partition is affected. It should be considered that preliminary and subsequent elements on a superior level of detail could be affected, too. Concerning those, an analysis up to the fourth level of detail needs to be conducted in order to identify the specific preliminary and subsequent information objects.

\section{Conclusion}

This paper focused on business processes in the field of m-business, called mobile business processes due to their special characteristics of a location uncertainty and cooperation with external resources from the process' point of view. The according definition of mobility is task-oriented, abstracting completely from potentially exis ting information systems. At this point, we see a need for research because in our experience, no comprehensive definition of mobility that includes the different aspects like logical, technical, or application-related mobility exists. Furthermore, it was shown that the application of mobile technology is usually technology-driven. The economic benefit of such a solution is often not exactly quantifiable in advance. Especially in large organisations with various business-critical processes and numerous involved persons such an approach is not applicable. Thus, we proposed a procedure to systematically analyse mobile potentials in business processes. The first step of this procedure was conducted using the Mobile Process Landscaping method and illustrated using a simple example from the insurance industry. At this point, we see a need for further research in order to integrate the shown procedure into the established approaches for modeling business processes. Finally, the drafted procedure aims to support the development of mobile information systems whose characteristics are not defined by mobile technology, but are rather deduced from the requirements of newly designed mobile business processes.

\section{References}

1. Scheer, A.: Business process engineering: reference models for industrial enterprises. Springer, Tokyo (1998)

2. Gruhn, V., Wellen, U.: Software Support for Distributed Business Processes. Proceedings of the Sixth Asia Pacific Software Engineering Conference. IEEE Computer Society Press, (1999) 200-206

3. Craighead, C. W., Shaw, N. G.: Ecommerce value creation and destruction: a resource-based, supply chain perspective. ACM SIGMIS Database 2 (2003) 39-49 
4. Dustdar, S., Gall, H.: Architectural concerns in distributed and mobile collaborative systems. Journal of Systems Architecture 49 (2003) 457-473

5. van der Heijden, H., Valiente, P.: Mobile Business Processes: Cases from Sweden and the Netherlands. Stockholm School of Economics, SSE/EFI Working Paper Series in Business Administration, 14 (2002)

6. Hammer, M., Champy, J.: Reengineering the corporation: a manifesto for business revolution. Brealey, London (1993)

7. Davenport, T. H.: Process innovation: reengineering work through information technology. Harvard Business School Press, Boston, Mass. (1993)

8. Valiente, P., van der Heijden, H.: A method to identify opportunities for mobile business processes. Stockholm School of Economics, SSE/EFI Working Paper Series in Business Administration, 10 (2002)

9. Laudon, K. C., Laudon, J. P.: Management Information Systems: managing the digital firm. Prentice Hall, Upper Saddle River, NJ (2002)

10. Köhler, A., Gruhn, V.: Mobile Process Landscaping am Beispiel von Vertriebsprozessen in der Assekuranz. In: Pousttchi, K., Turowski, K. (eds.): Mobile Economy - Transaktionen, Prozesse, Anwendungen und Dienste. GI-Lecture Notes in Informatics, P-25. Köllen Druck + Verlag GmbH, Bonn, (2003) 12-24

11. Gruhn, V., Wellen, U.: Process Landscaping: Modeling Distributed Processes and Proving Properties of Distributed Process Models. Lecture Notes in Computer Science, 2128. Springer, (2001) 103-125

12. Noor, N. M. M., Papamichail, K. N., Warboys, B.: Process Modeling for Online Communications in Tendering Processes. Proceedings of the 29th EUROMICRO Conference 'New Waves in System Architecture'. IEEE Computer Society, (2003) $17-24$

13. Ritz, T., Stender, M.: Modeling of B2B Mobile Commerce Processes. 17th International Conference on Production Research ICPR-17. Virginia Tech, Blacksburg, (2003)

14. Gruhn, V., Wellen, U.: Structuring Complex Software Processes by 'Process Landscaping'. EWSPT European Workshop on Software Process Technology, Kaprun, Austria. Lecture Notes in Computer Science, 1780. Springer, (2000) 138149

15. Aalst, W. v. d., Hee, K. M. v.: Workflow management: models, methods, and systems. MIT Press, Cambridge, Mass. (2002)

16. OMG: Unified Modeling Language Specification. http://www .omg.org (2001)

17. Scheer, A., Nüttgens, M.: ARIS Architecture and Reference Models for Business Process Management. In: van der Aalst, W., Desel, J., Oberweis, A. (eds.): Business Process Management - Models, Techniques, and Empirical Studies. LNCS 1806, Berlin et al., (2000) 366-379

18. White, S. A.: Business Process Modeling Notation. Business Process Management Initiative, BPMI.org (2003)

19. Arkin, A.: Business Process Modeling Language. Business Process Management Initiative, BPMI.org (2002)

20. http://xml.coverpages .org/bpm.html. 